\title{
State-of-the-Art Fuel Cell Voltage Durability and Cost Status 2018 Composite Data Products
}

Genevieve Saur, Jennifer Kurtz, Huyen Dinh, Chris Ainscough, Shaun Onorato

May 2018 


\section{Projected Hours to $10 \%$ Stack Voltage Degradation}

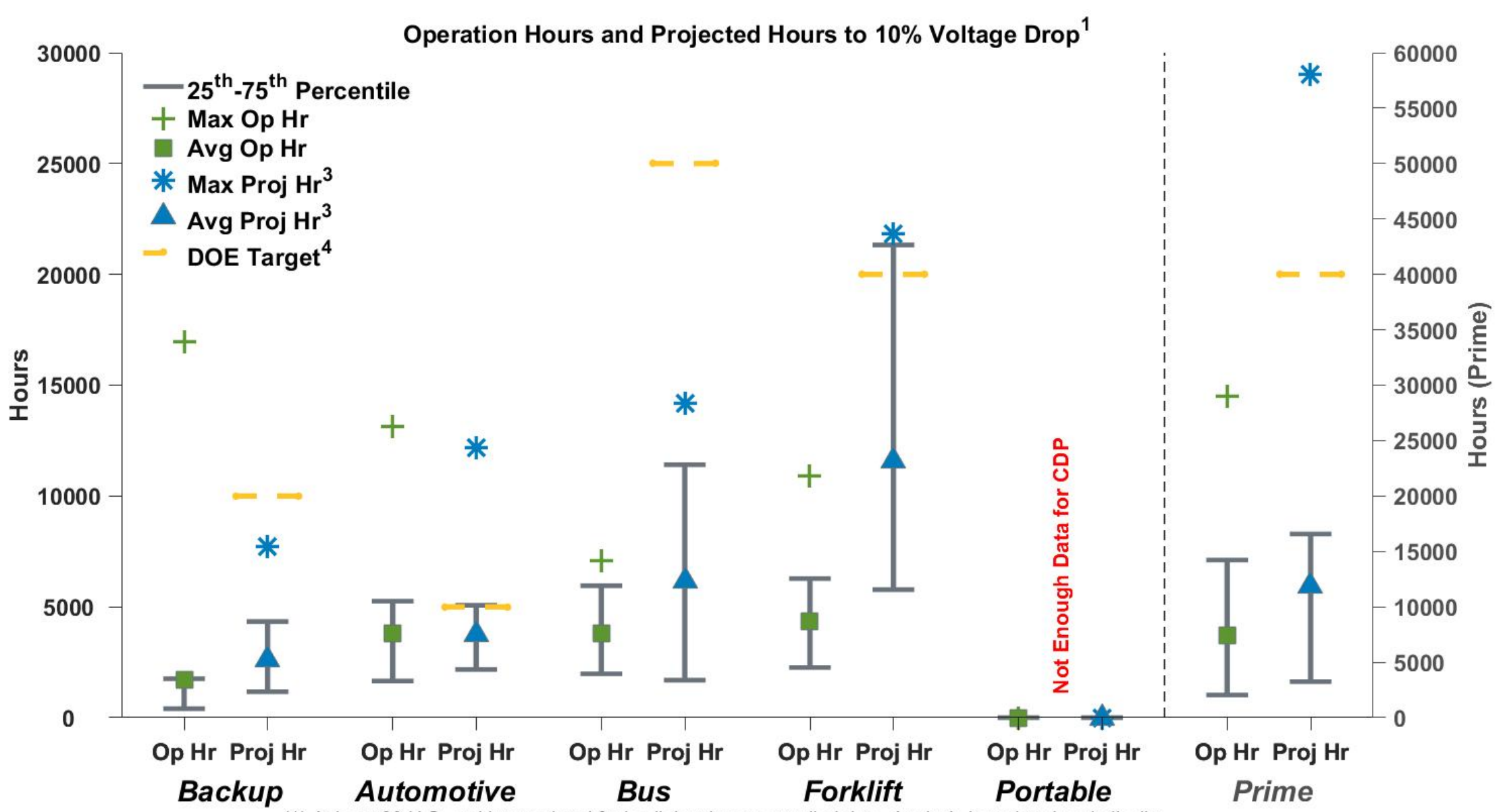

(1) At least 23 U.S. and international fuel cell developers supplied data. Analysis is updated periodically.

Prime

(2) PEMFC, DMFC \& SOFC data from lab tested, full active area short stacks and systems with full stacks. Data generated from constant load, transient load, and accelerated testing between 2004 and 2017.

(3) The DOE $10 \%$ voltage degradation metric is used for assessing voltage degradation; it may not be the same as end-of-life criteria and does Created: May-23-18 3:19 PM | Data Range: 2004Q1-2017Q4 not address catastrophic failure modes.

(4) DOE targets are for real-world applications; refer to Hydrogen, Fuel Cells, \& Infrastructure Technologies Program Plan. 


\section{CDP-LAB-01: Lab Data Projected Hours to $10 \%$ Stack Voltage Degradation-Simplified}

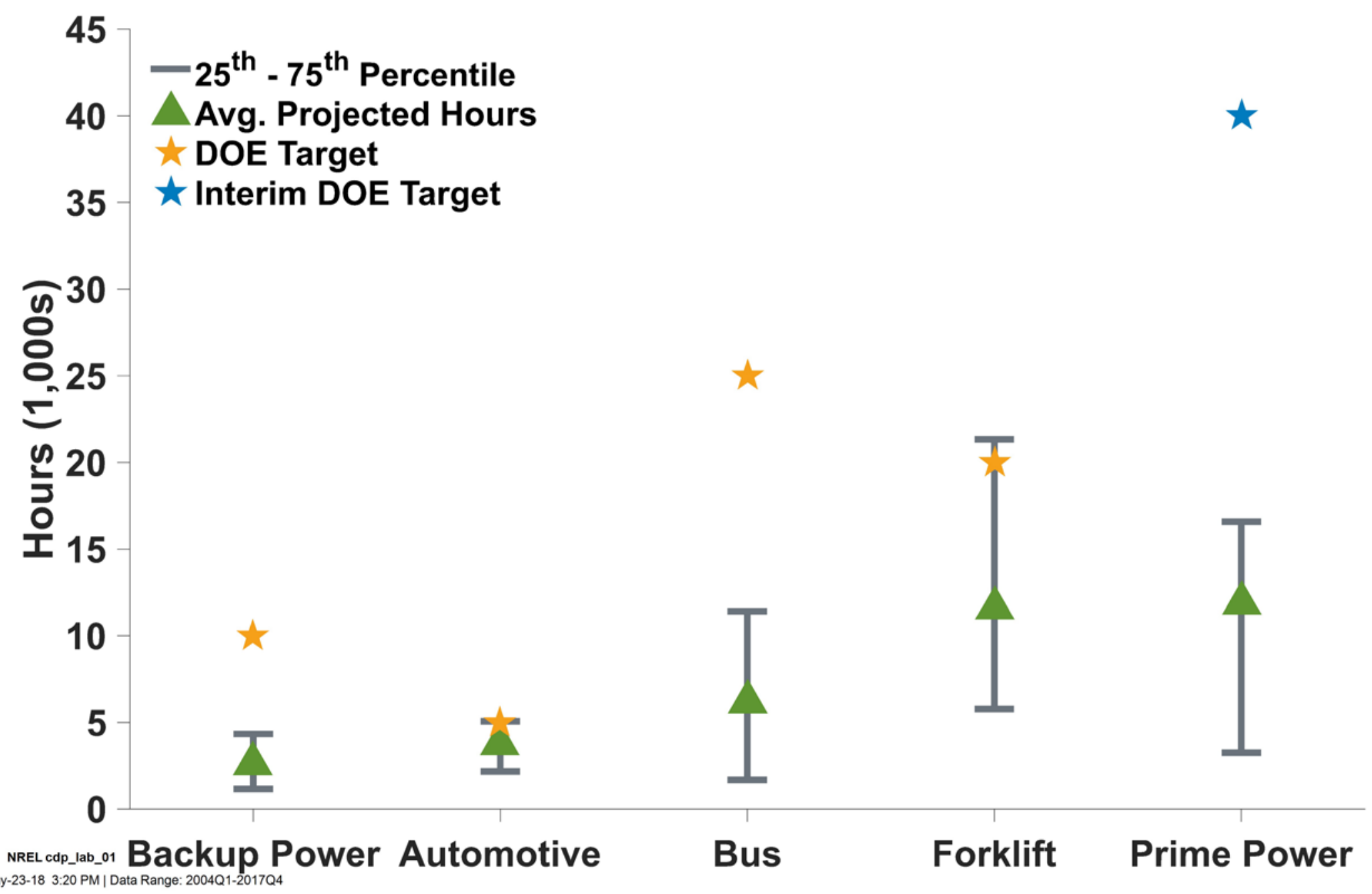




\section{CDP-LAB-02: Durability Lab Data Projection Sensitivity to Voltage Degradation Levels}

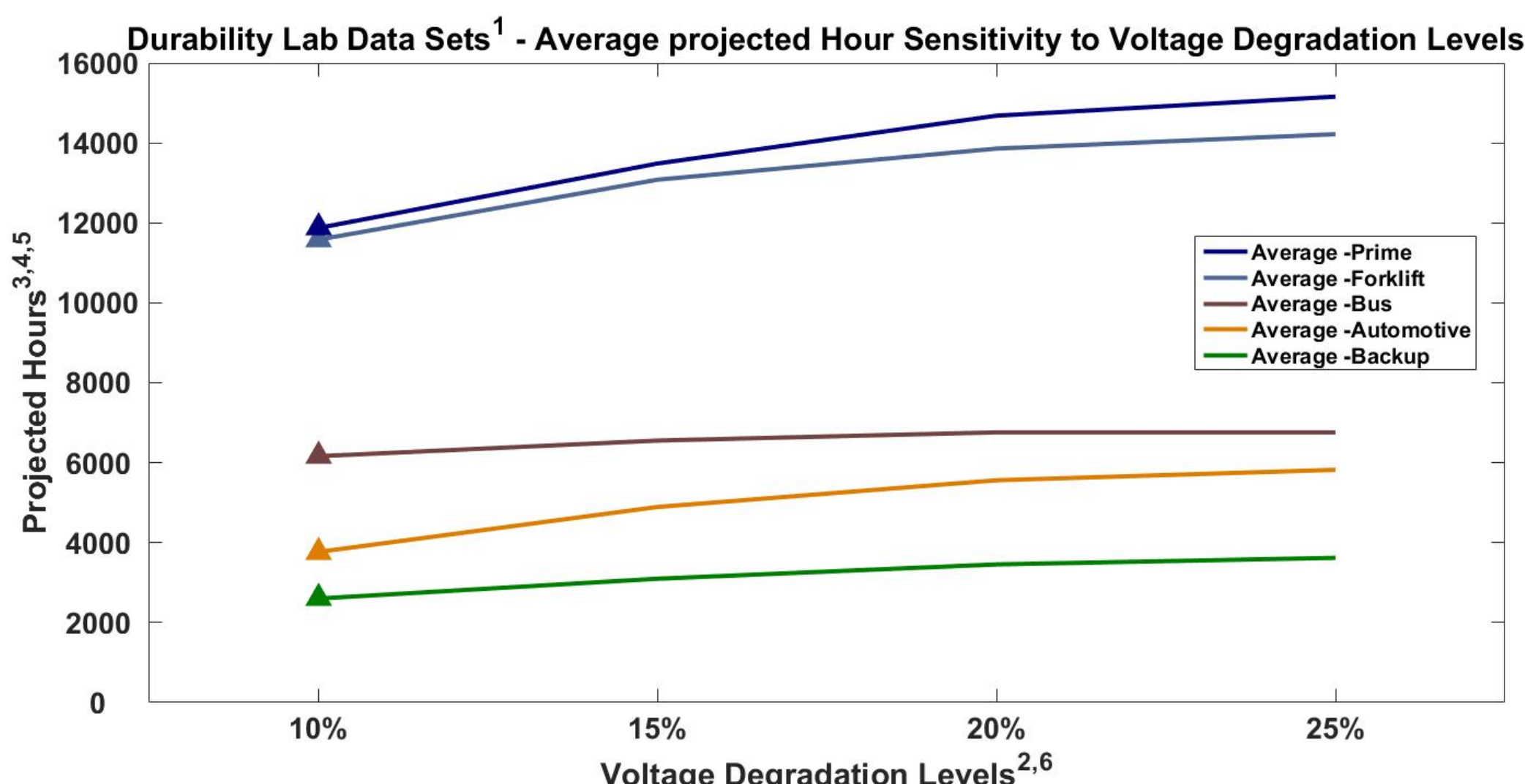

(1) PEM \& SOFC data from lab tested, full active area short stacks and systems with full stacks. Data generated from constant load, transient load, and accelerated testing between 2004 and 2017.

(2) $10 \%$ Voltage degradation is a DOE metric for assessing fuel cell performance.

(3) Curves generated using the average of each application at various voltage degradation levels.

(4) The projection curves display the sensitivity to percentage of voltage degradation, but the projections do not imply that all stacks will (or do) operate at these voltage degradation levels.

(5) Projections may be limited by demonstrated operation hours to minimize extrapolations.

Created: May-23-18 3:24 PM | Data Range: 2004Q1-2017Q4 (6) The voltage degradation levels are not an indication of an OEM's end-of-life criteria and do not address catastrophic stack failures such as membrane failure. 


\section{CDP-LAB-03: Field and Lab Durability Projection Comparison CDP for Automotive Category}

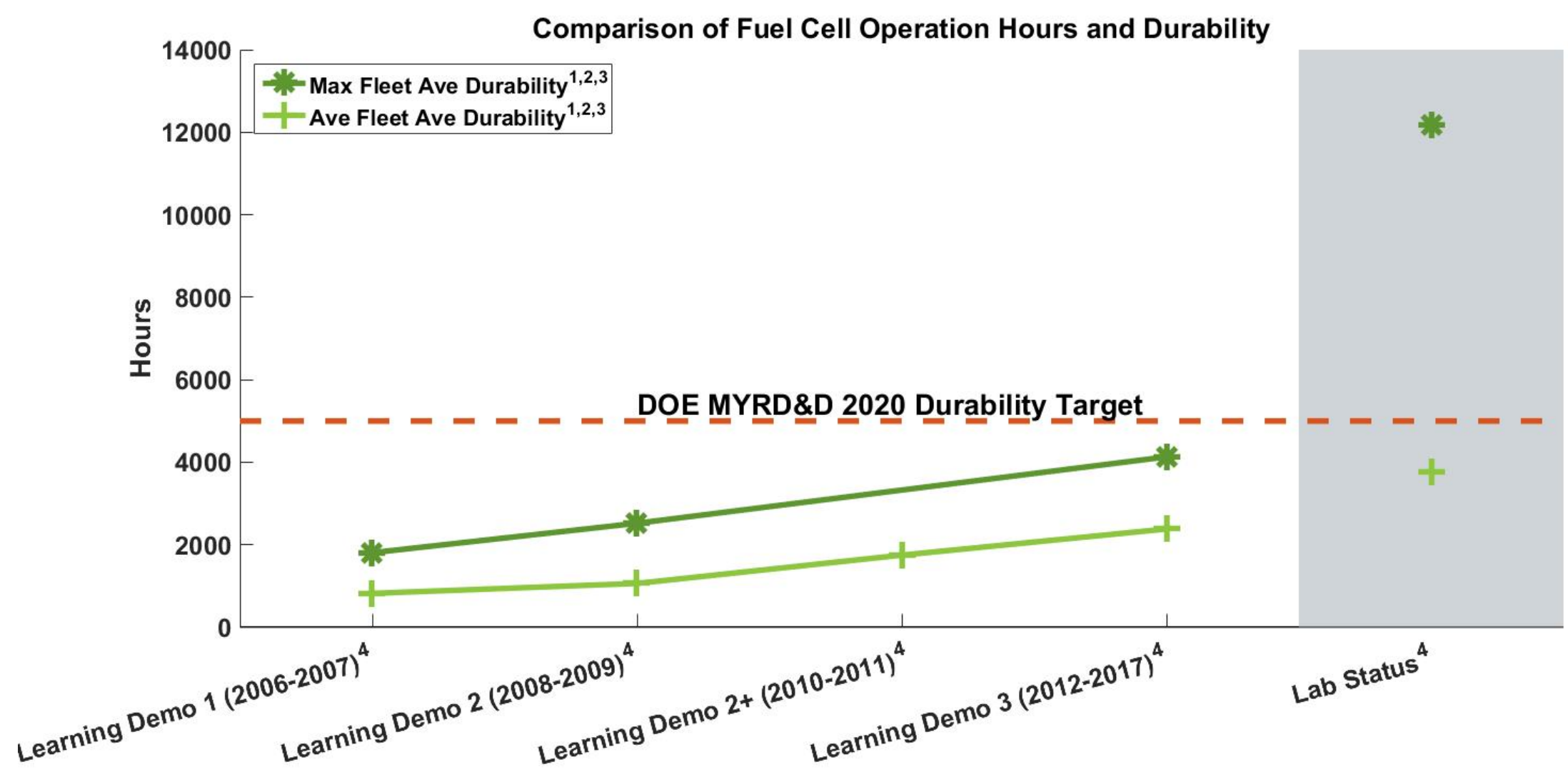

1. Durability based on voltage degradation to $10 \%$ lower than beginning of life voltage. $10 \%$ voltage drop level is a DOE metric for assessing fuel cell durability.

2. Projections using on-road data are calculated at approximately $55 \%-65 \%$ rated stack current.

3. $10 \%$ voltage drop is NOT an indication of an OEM's end-of-life criteria and projections do not address catastrophic stack failure.

4. Maximum operational hours: 2,375 (LD1); 1,200 (LD2); 5,648 (Current FCEV Analysis); 13,129 (Lab

Status); Maximum operational hours not reported in Learning Demonstration 2 continuation (LD2+)

(2010-2011). 


\section{CDP-LAB-04: Cumulative Operation Hours by Application and Number of Data Sets}

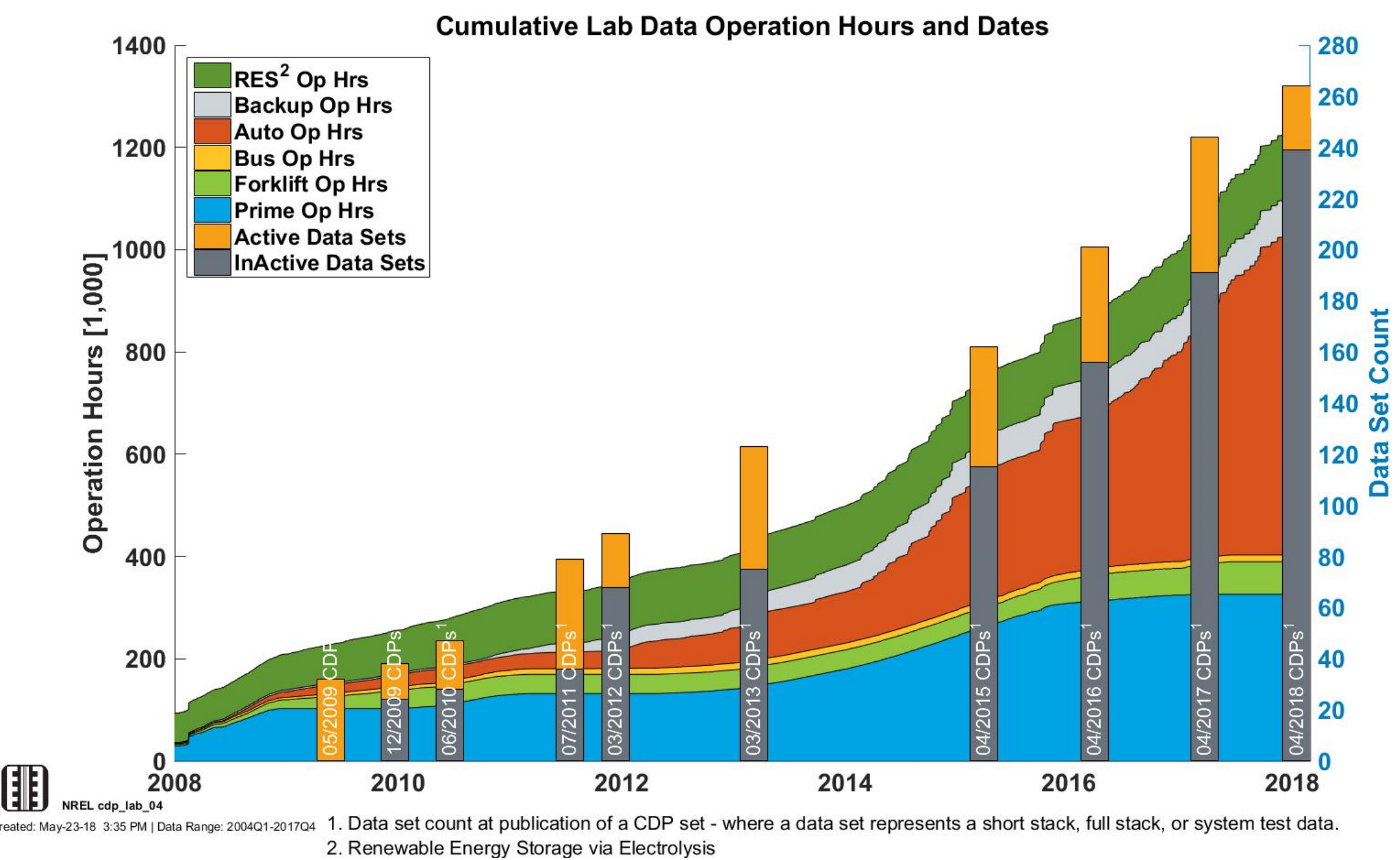




\section{CDP-LAB-06: Data Set Power Capability}

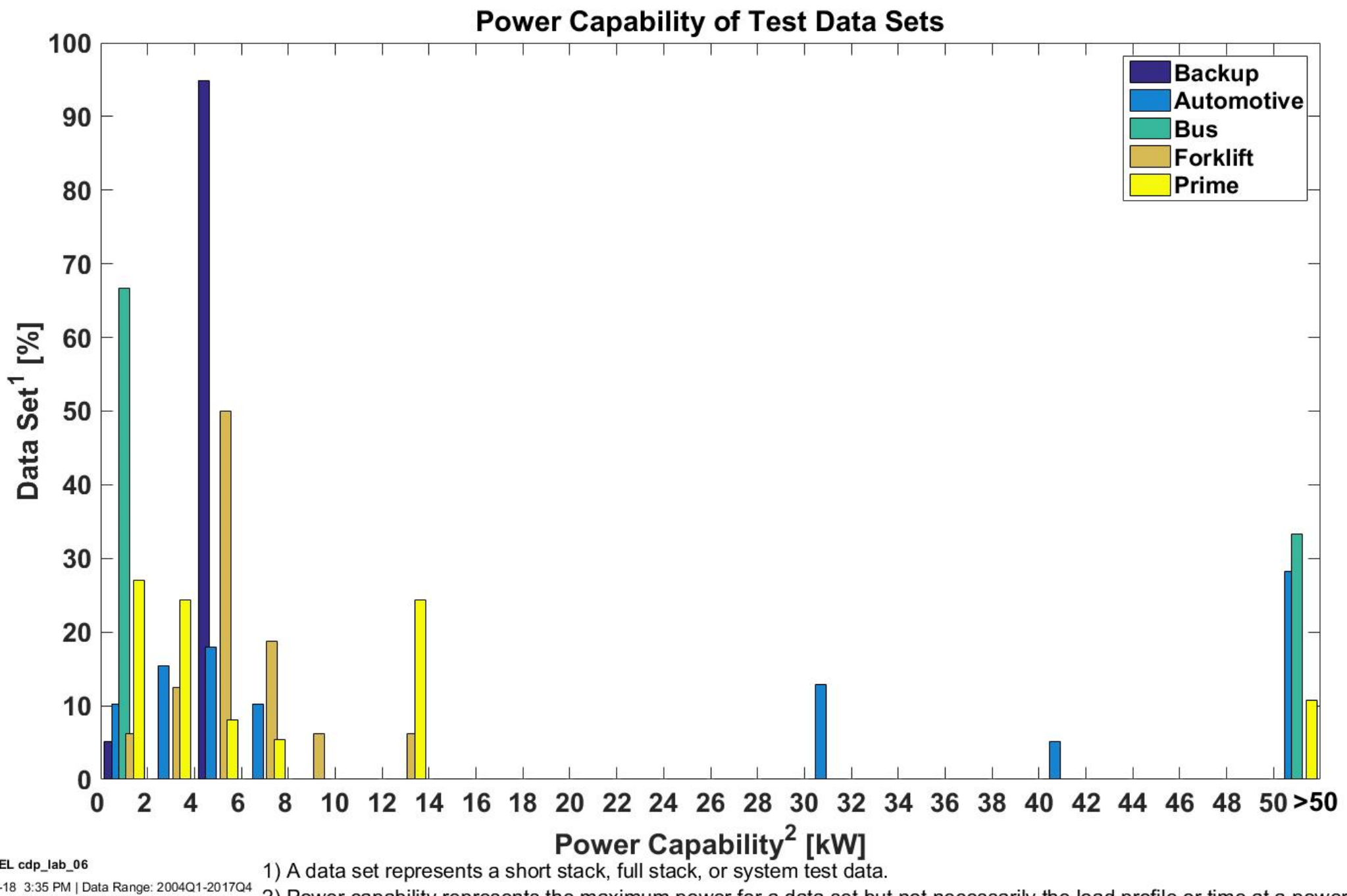

2) Power capability represents the maximum power for a data set but not necessarily the load profile or time at a power level. 


\section{CDP-LAB-07: Data Set Operation Hours and the Percentage of Data Sets That Have Passed 10\% Voltage Degradation}

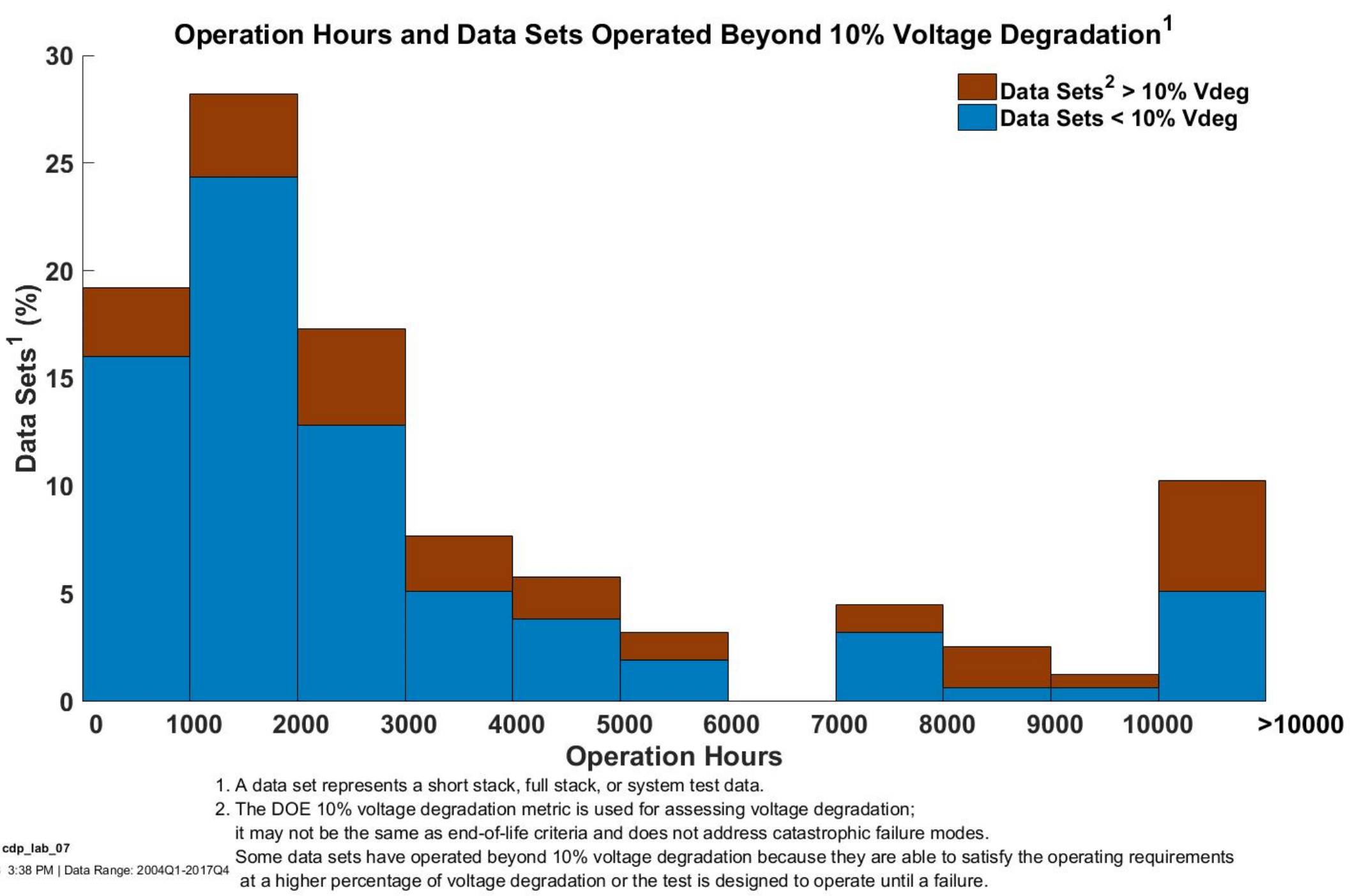




\section{CDP-LAB-08: Voltage Degradation by Configuration and Test}

\section{Condition}

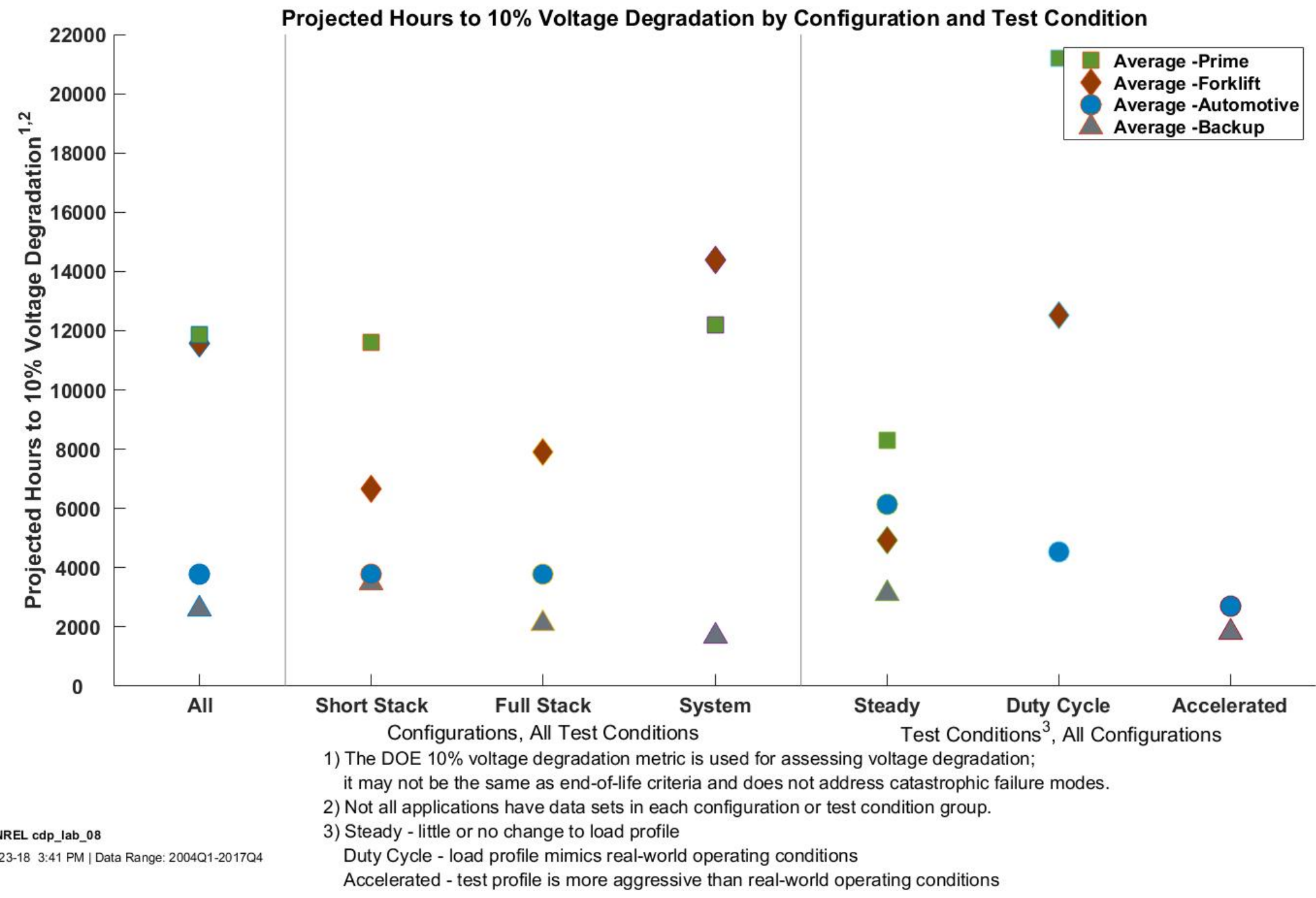




\section{CDP-LAB-09: Data Set Configuration}

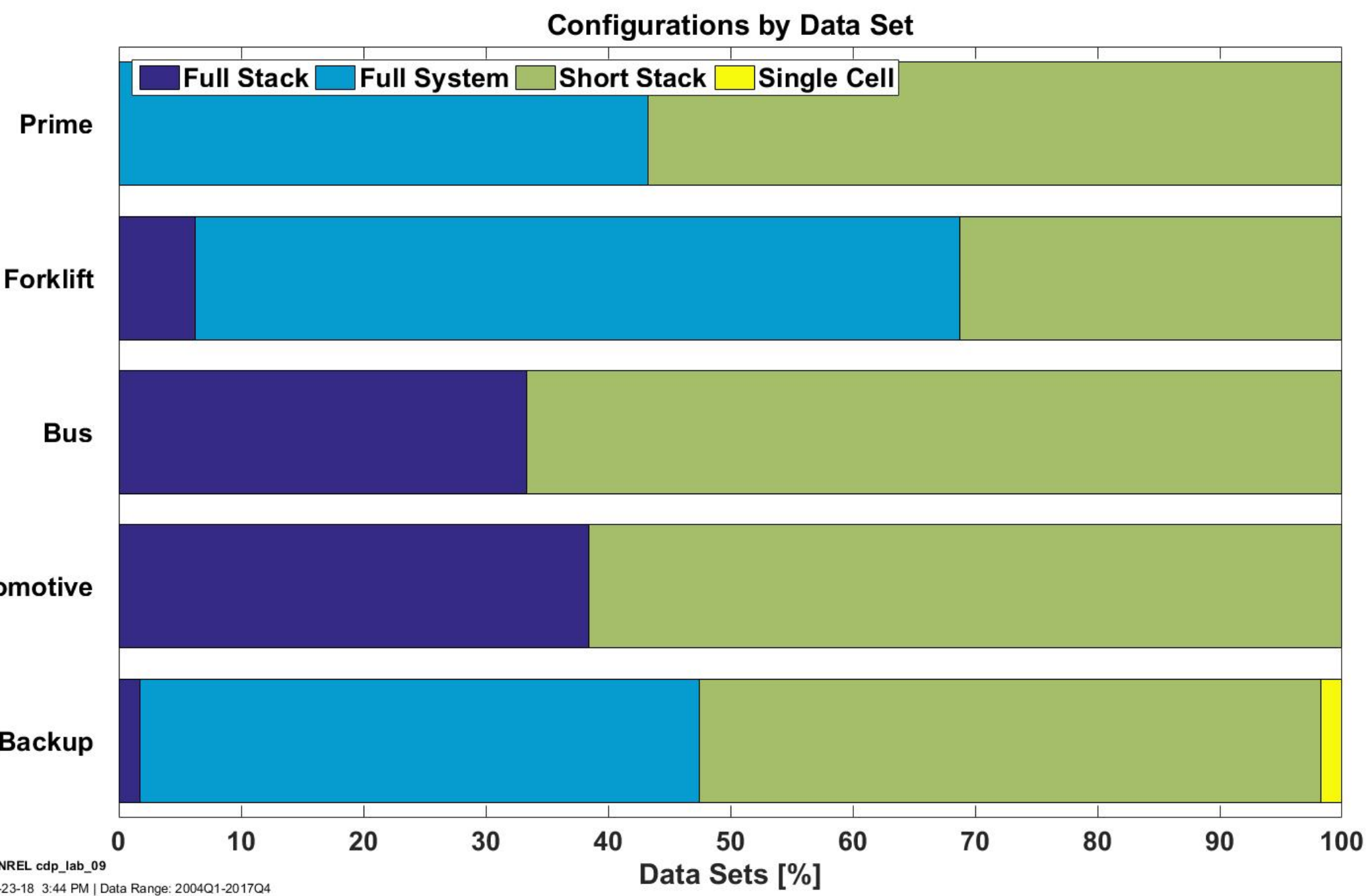




\section{CDP-LAB-12: Data Set Fuel}

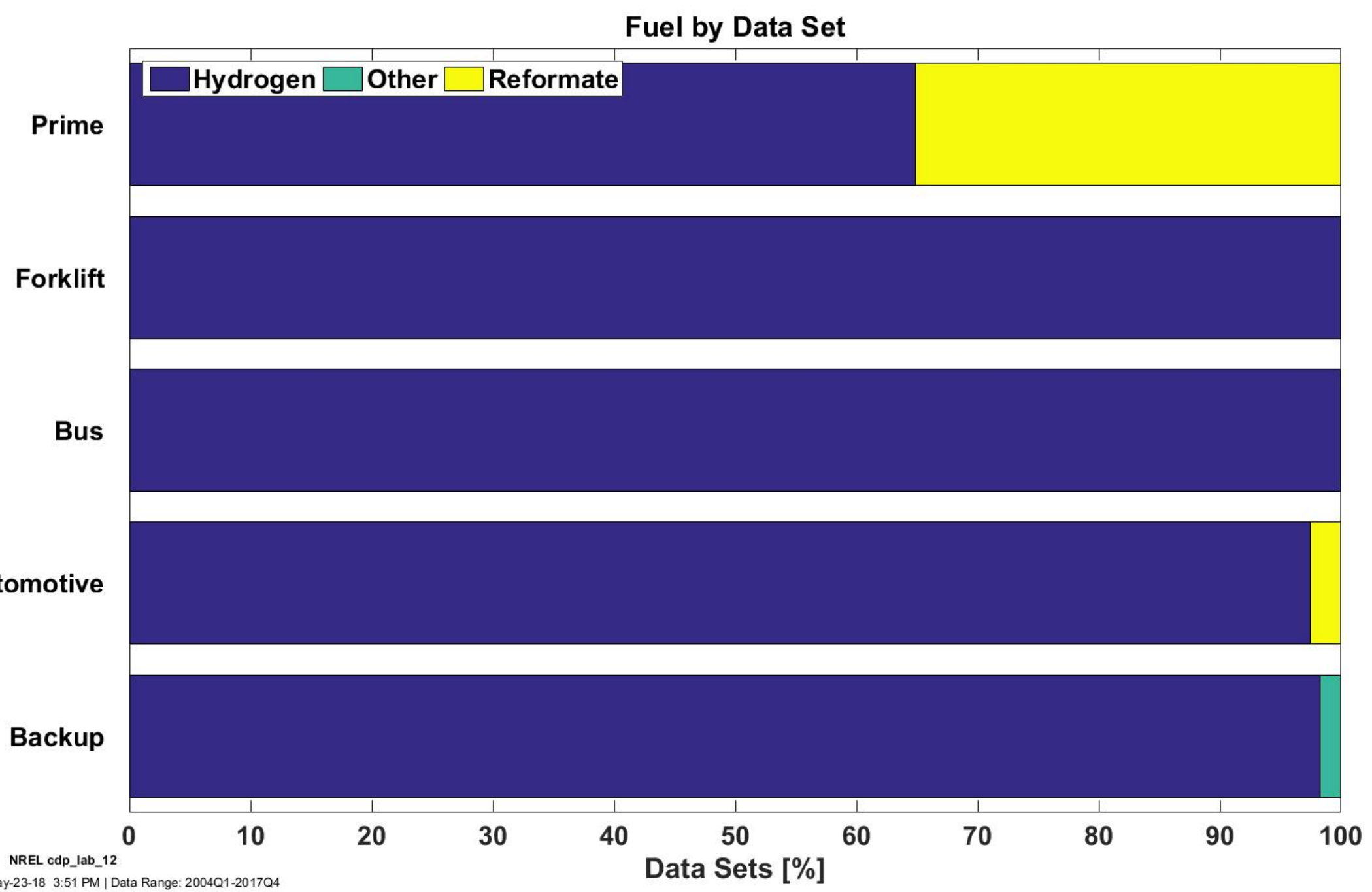




\section{CDP-LAB-13: Data Set Test Conditions}

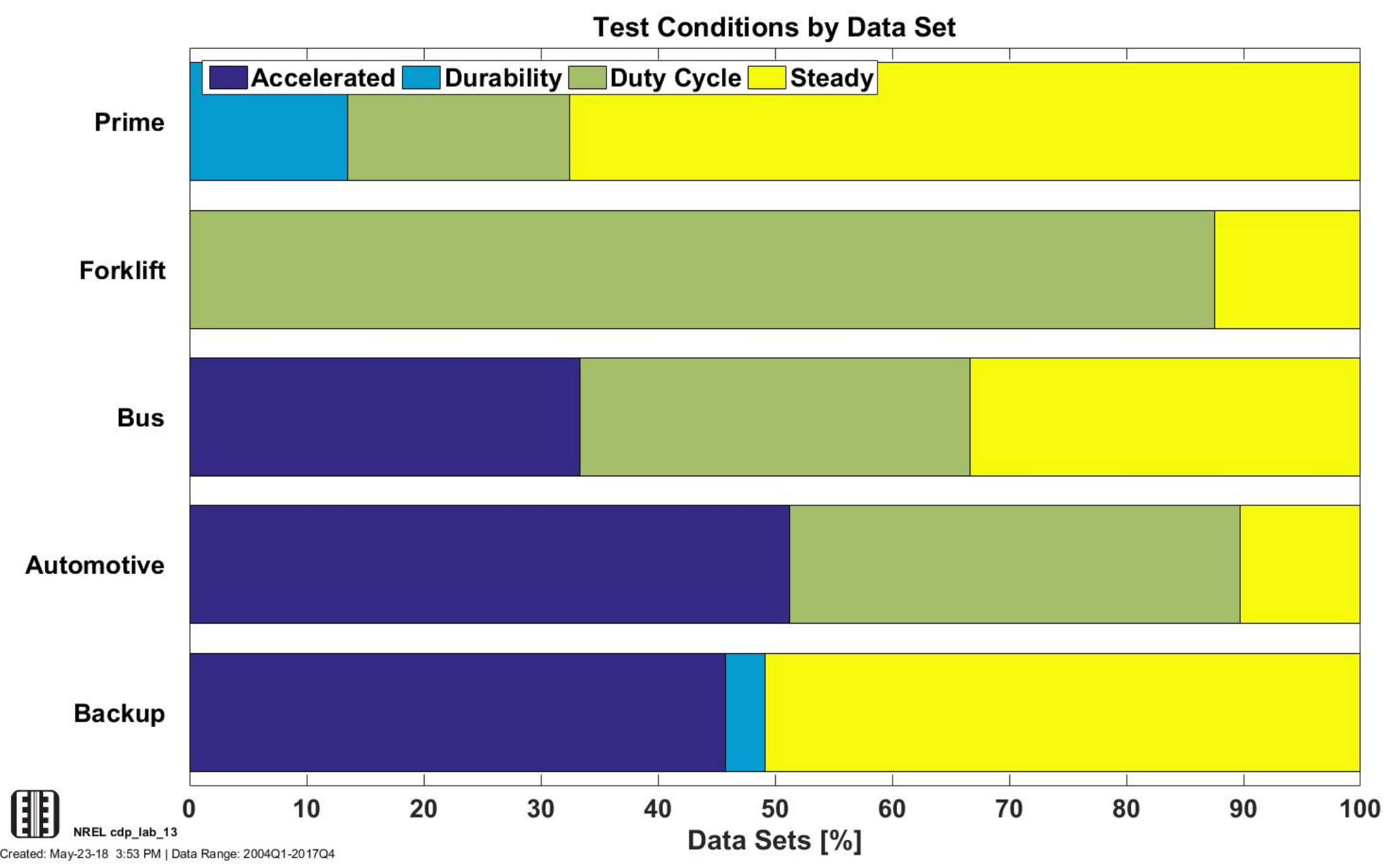




\section{CDP-LAB-14: Current Density Points}

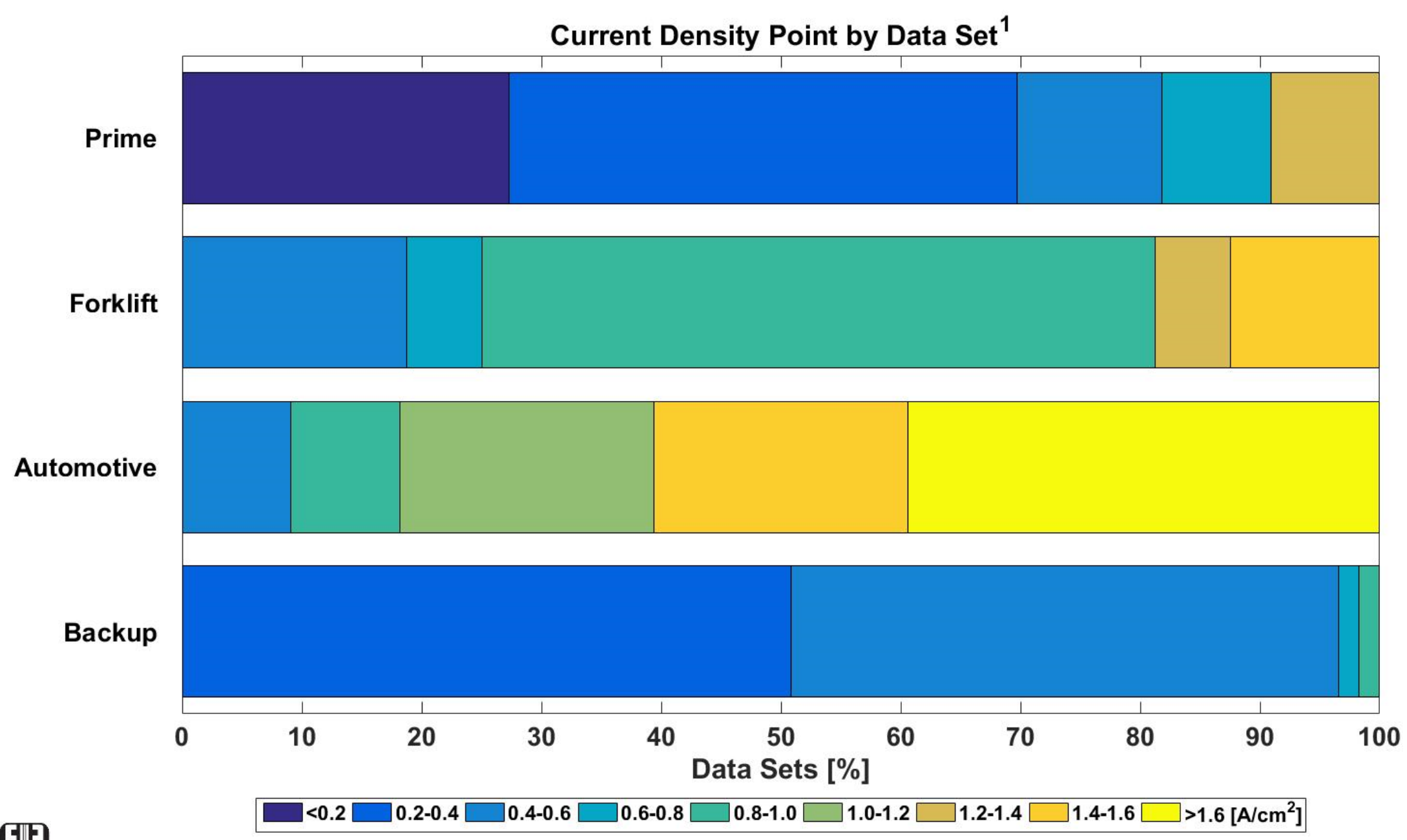




\section{CDP-LAB-15: Low Volume Price of Current Fuel Cell Systems}

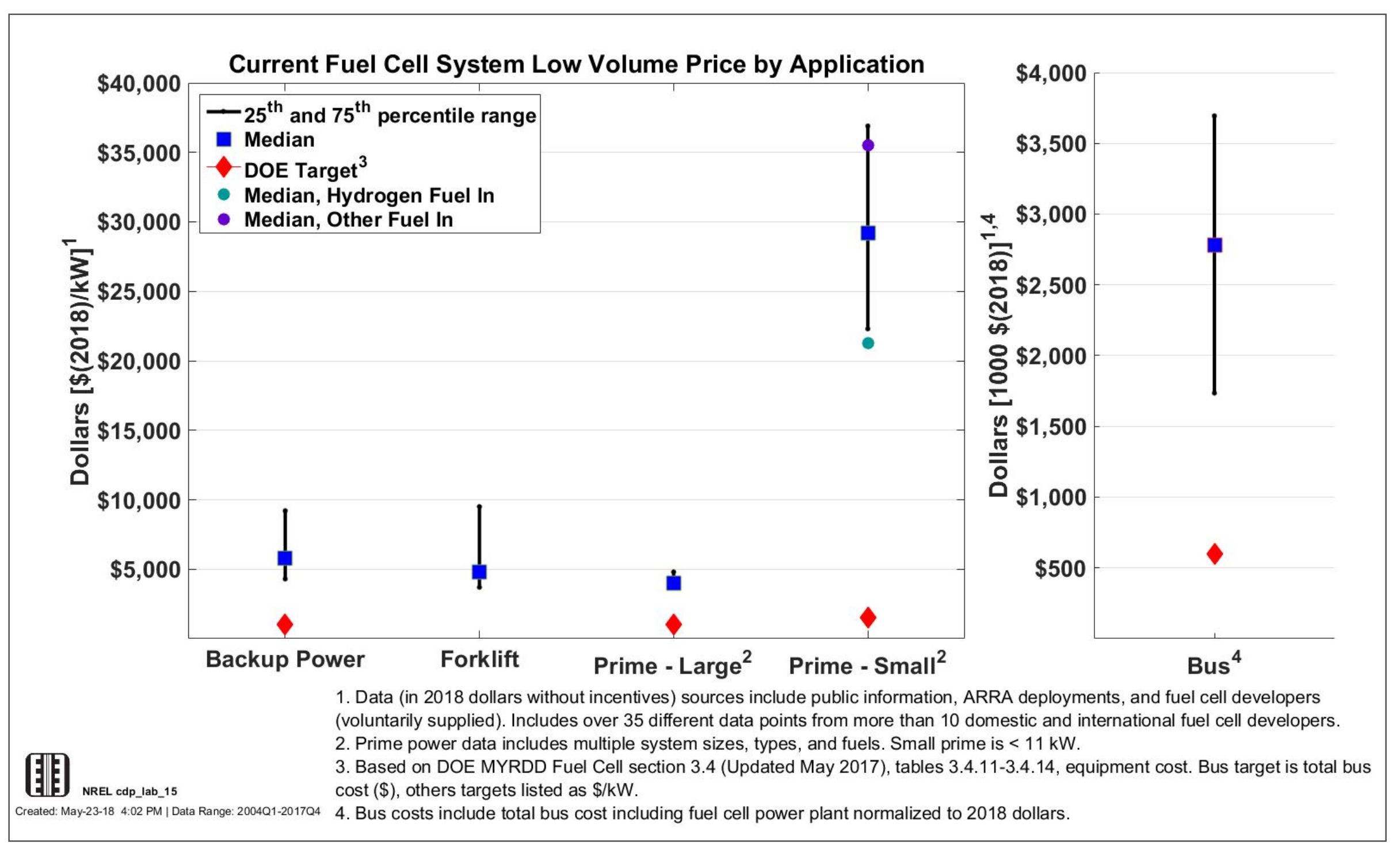




\section{CDP-LAB-16: Average Projected Voltage Degradation by Year}

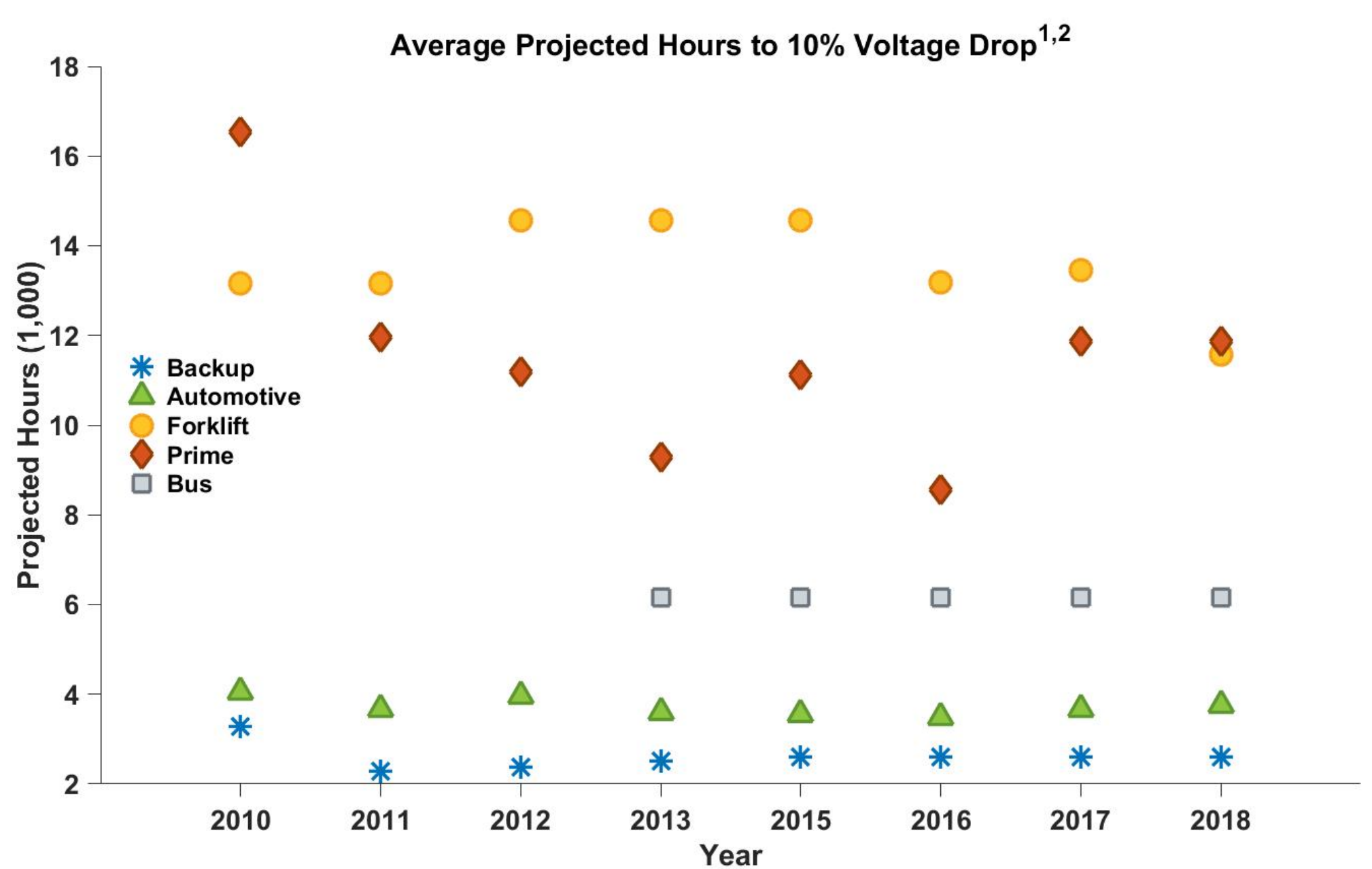

(1) The DOE $10 \%$ voltage degradation metric is used for assessing voltage degradation; it may not be the same as end-of-life criteria and does not address catastrophic failure modes.

Created: May-23-18 3:58 PM | Data Range: 2004Q1-2017Q4 (2) At least 23 developers supplied data, including international. Analysis is updated periodically. Durability resuls were not published in 2014. 


\section{CDP-LAB-17: Voltage Degradation by Year}

Projected Hours to $10 \%$ Voltage Drop $p^{1,2}$

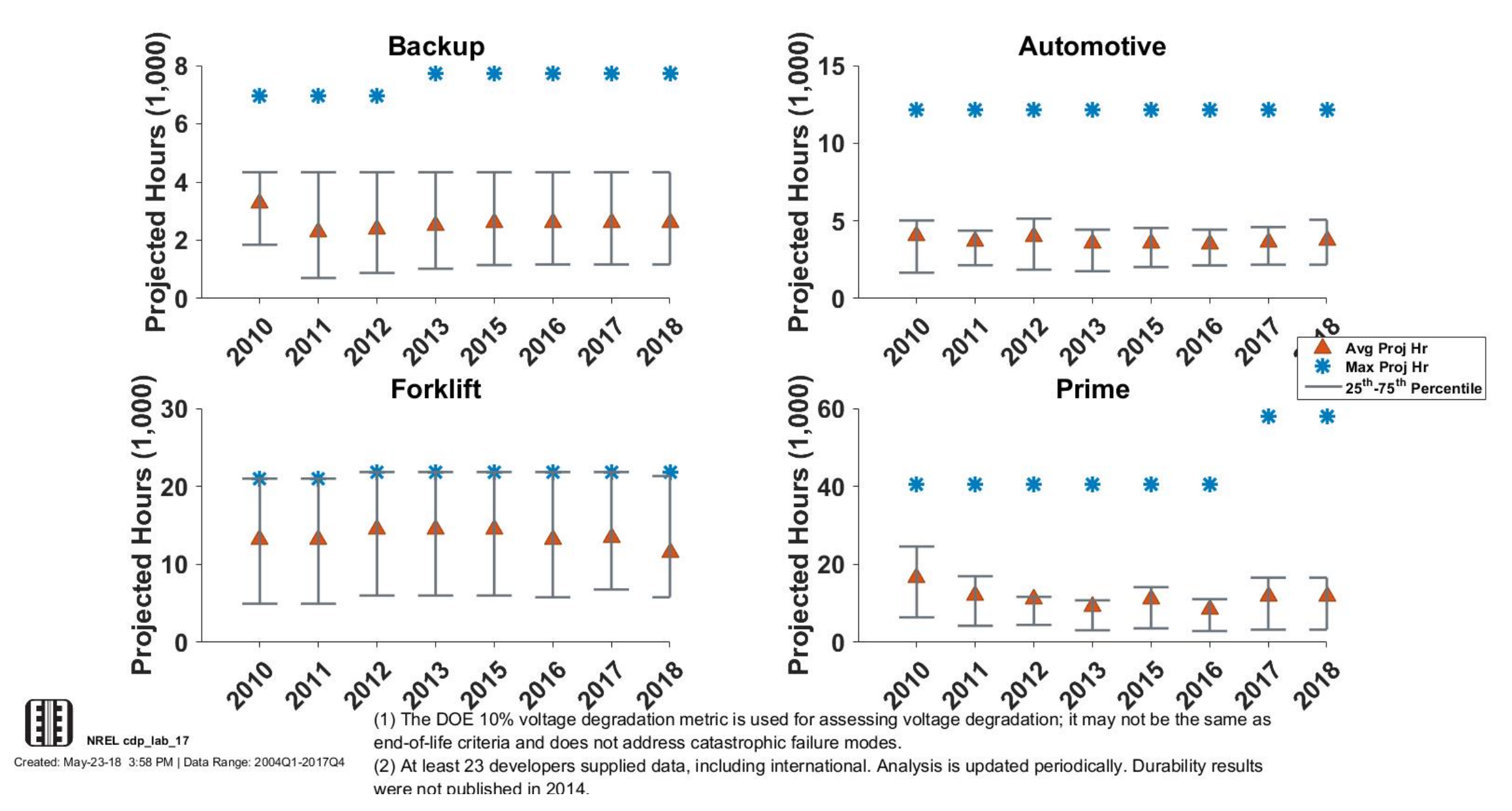




\section{CDP-LAB-18: Electrolyzer Operation Hours and Voltage Degradation}

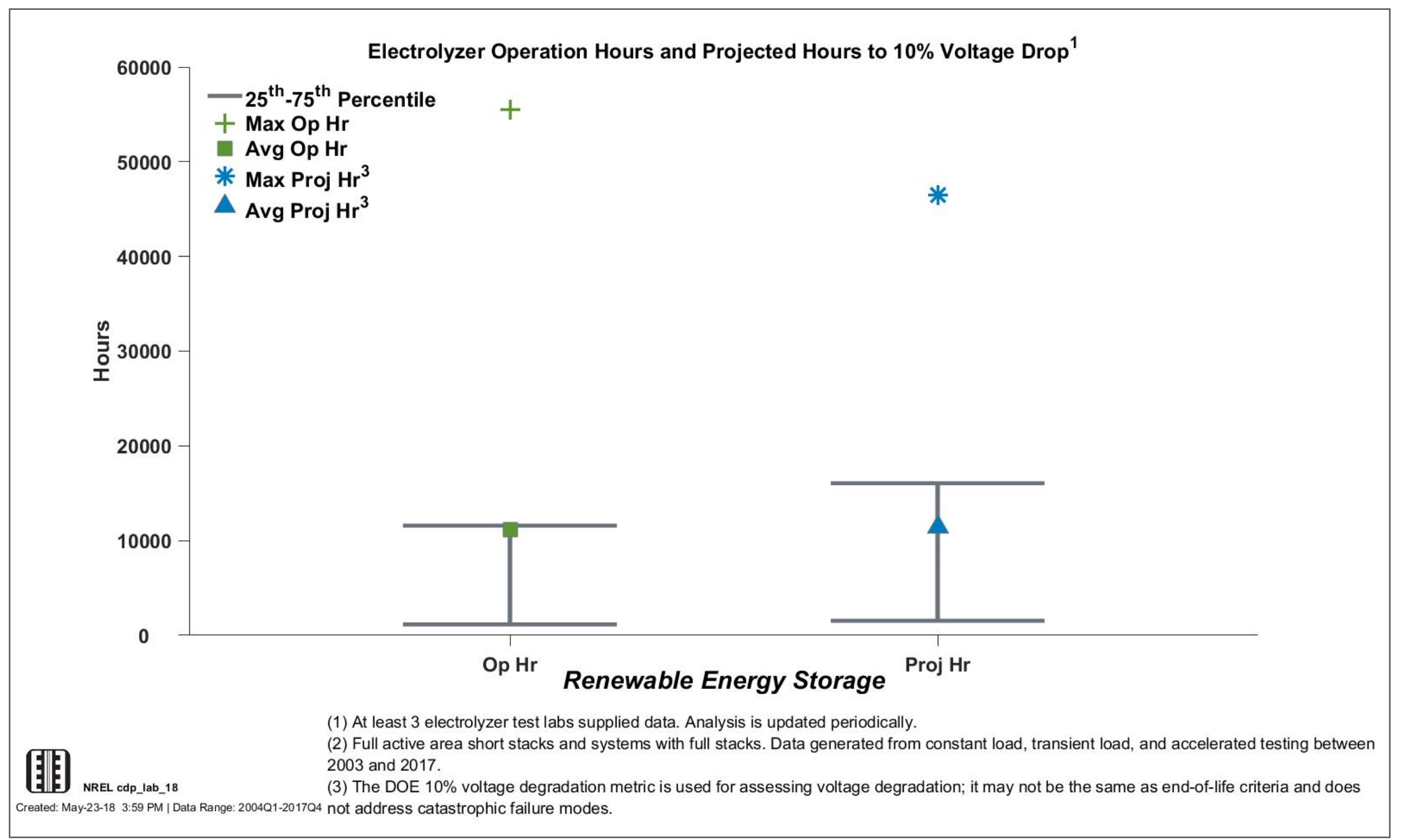




\section{CDP-LAB-19: Lab Durability Summary Table}

\section{Lab Durability Summary Table}

\begin{tabular}{|c|c|c|}
\hline Application & $\begin{array}{c}2020 \text { DOE } \\
\text { Durability Target }^{a}\end{array}$ & $\begin{array}{c}\text { Lab Status - Ave } \\
\text { Hrs to } 10 \% \text { Voltage } \\
\text { Degradation }^{b}\end{array}$ \\
\hline $\begin{array}{l}\text { Light Duty } \\
\text { Automotive }\end{array}$ & 5,000 Hours & 3,800 \\
\hline Public Transit & 25,000 Hours & 6,200 \\
\hline 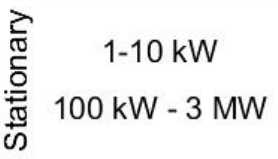 & $\begin{array}{c}0.3 \% / 1,000 \text { Hours } \\
80,000 \text { Hours }\end{array}$ & 11,900 \\
\hline Forklift & $\begin{array}{c}20,000 \text { Hours - Target } \\
\text { Under Review }\end{array}$ & 11,600 \\
\hline Backup & 10,000 Hours & 2,600 \\
\hline
\end{tabular}

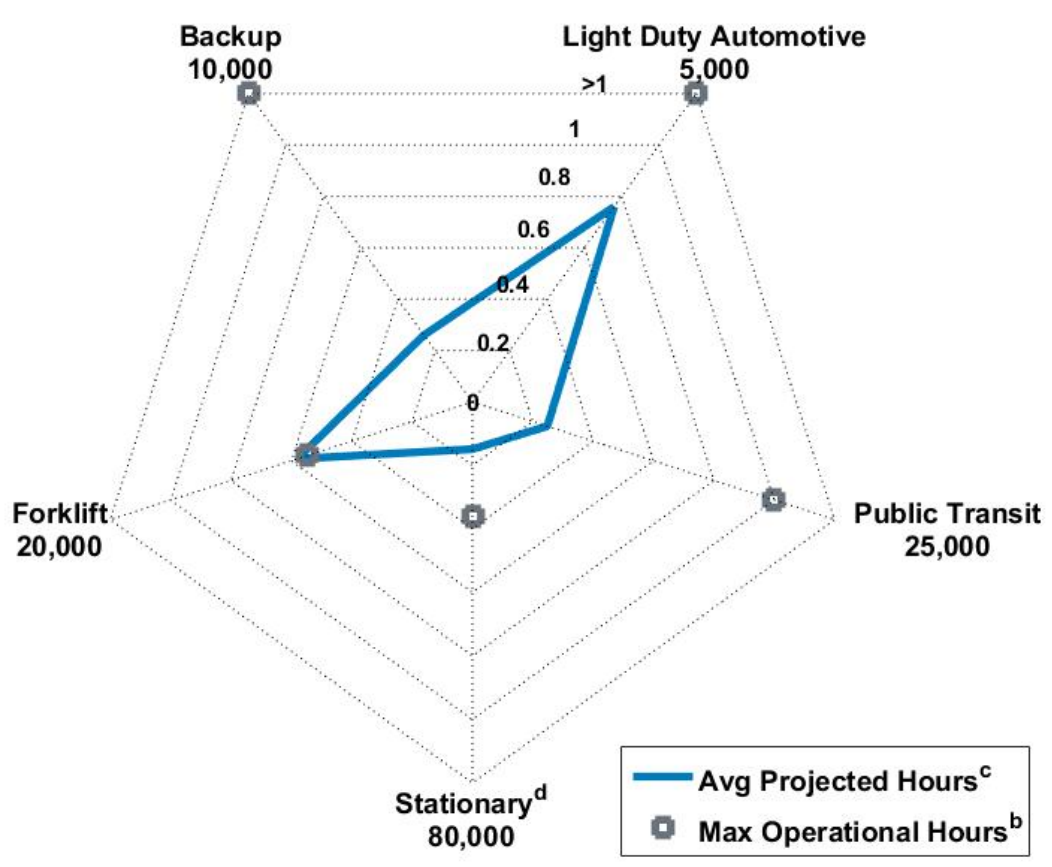

a. Fuel Cell Technolgies Office Multi-Year Research, Development, and Demonstration Plan (MYRDD)

<https://energy.gov/eere/fuelcells/downloads/fuel-cell-technologies-office-multi-year-research-development-and-22>

b. Current results are available at http://www.nrel.gov/hydrogen/images/cdp_lab_01.jpg (Updated 04/2018) or from on-road results (2017 Annual FCB results www.nrel.gov/docs/fy18osti/70075.pdf)

c. Results are a fraction of the 2020 targets in the MYRDD.

d. Stationary $100 \mathrm{~kW}-3 \mathrm{MW}$ vs DOE target of $80,000 \mathrm{hrs}$. 


\section{CDP-LAB-20: Platinum Loading}

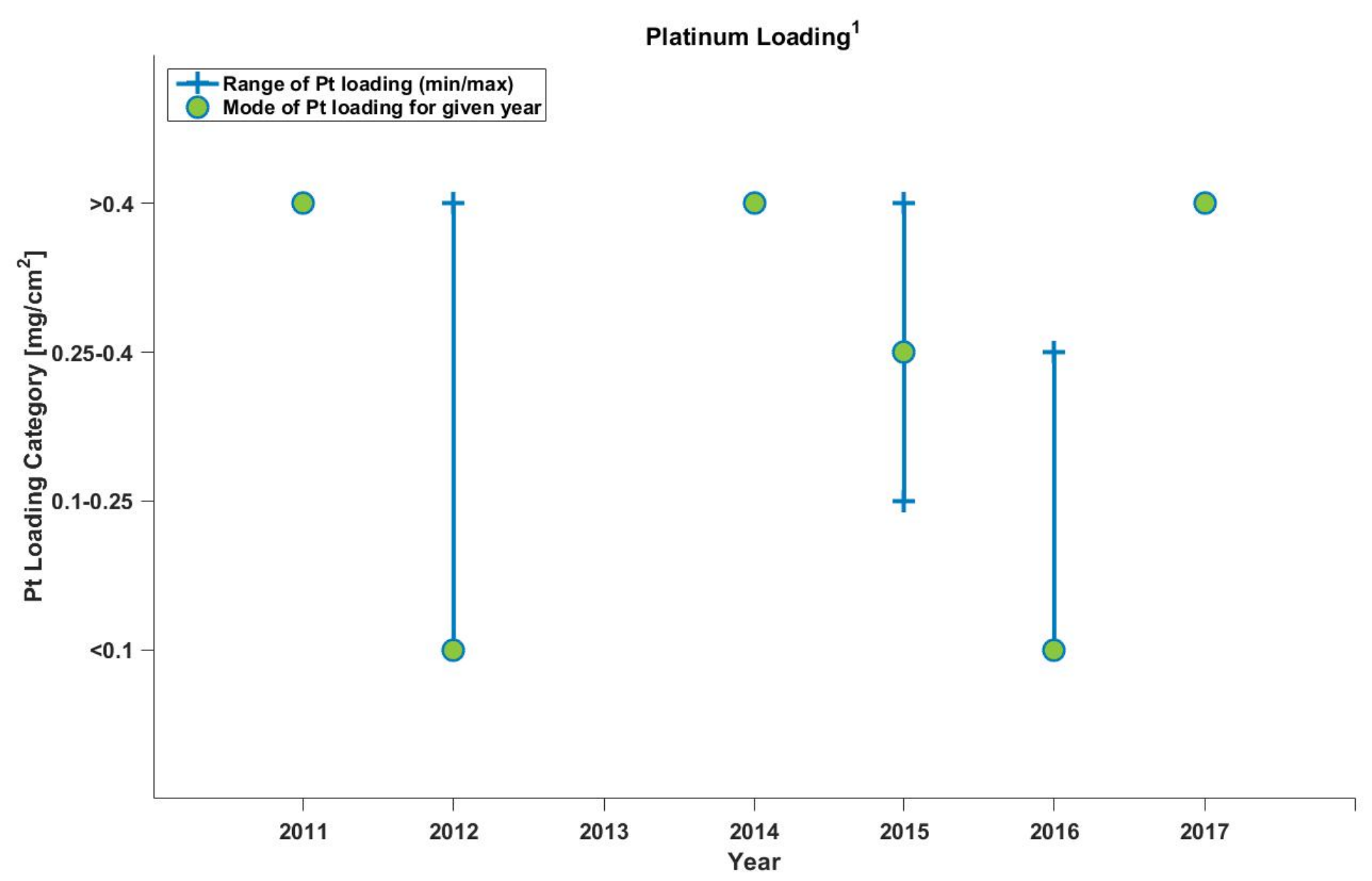




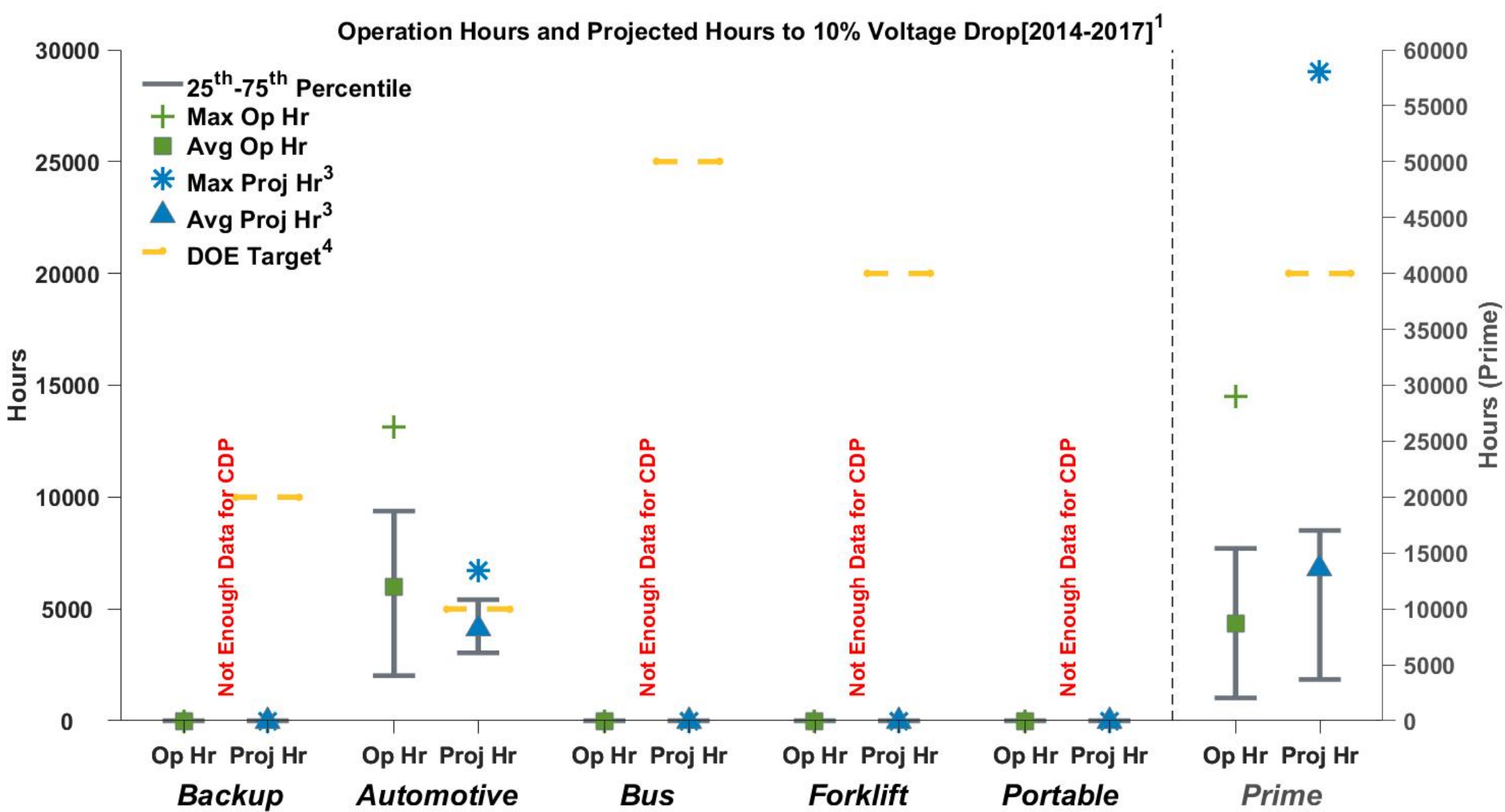

(1) Partial data from 2014-2017 only, full dataset includes least 23 U.S. and international fuel cell developers. See CDP-Lab-01 for full data set. (2) PEMFC, DMFC \& SOFC data from lab tested, full active area short stacks and systems with full stacks. Data generated from constant load, transient load, and accelerated testing between 2004 and 2017.

(3) The DOE $10 \%$ voltage degradation metric is used for assessing voltage degradation; it may not be the same as end-of-life criteria and does Created: May-23-18 4:00 PM | Data Range: 2004Q1-2017Q4 not address catastrophic failure modes.

(4) DOE targets are for real-world applications; refer to Hydrogen, Fuel Cells, \& Infrastructure Technologies Program Plan. 


\section{www.nrel.gov}

NREL/PR-5400-71642

This work was authored by Alliance for Sustainable Energy, LLC, the manager and operator of the National Renewable Energy Laboratory for the U.S. Department of Energy (DOE) under Contract No. DE-AC36-08GO28308. Funding provided by U.S. Department of Energy Office of Energy Efficiency and Renewable Energy Fuel Cell

Technologies Office. The views expressed in the article do not necessarily represent the views of the DOE or the U.S Government. The U.S. Government retains and the publisher, by accepting the article for publication, acknowledges that the U.S. Government retains a nonexclusive, paid-up, irrevocable, worldwide license to publish or reproduce the published form of this work, or allow others to do so, for U.S. Government purposes.
NATIONAL RENEWABLE ENERGY LABORATORY 